\title{
Resection of an anterior spinal cord AVM through a far-lateral approach
}

\author{
L. Madison Michael, M.D. and Jeffrey M. Sorenson, M.D. \\ Semmes Murphey Clinic / University of Tennessee, Memphis, TN
}

\begin{abstract}
A small arteriovenous malformation near the craniocervical junction with contributions from the anterior spinal artery was discovered in a young developmentally-delayed woman after she presented with altered mental status and evidence of subarachnoid hemorrhage. The malformation could not be completely treated with endovascular therapy, so it was resected through a far-lateral approach. This stereoscopic video demonstrates how to gain the exposure needed to address a lesion in this area.

The video can be found here: http://youtu.be/ByjPGm_eXLc.

(http://thejns.org/doi/abs/10.3171/2012.V2.FOCUS12161)
\end{abstract}

KEY WoRDS $\bullet \begin{aligned} & \text { arteriovenous malformation } \\ & \text { noid hemorrhage }\end{aligned} \quad$ video

Manuscript submitted May 5, 2012.

Accepted May 17, 2012.

Please include this information when citing this paper: DOI: 10.3171/2012.V2.FOCUS12161.

Address correspondence to: Jeffrey M. Sorenson, M.D., Semmes Murphey Clinic / University of Tennessee, Neurosurgery, 847 Monroe Avenue Suite 427, Memphis, TN 38163. email: jsorenson@ semmes-murphey.com. 